\title{
BARRIERS OF FINANCIAL ACCESS TO UTILISATION OF HEALTH CARE SERVICES TO WOMEN IN RURAL AREAS OF WEST BENGAL, INDIA: AN ANALYSIS OF A SAMPLE SURVEY
}

\author{
Yasmin Khatun ${ }^{1}$ and Shovan Ghosh ${ }^{2}$ \\ 1Ph.D, Research Scholar, Department of Geography, \\ Diamond Harbour Women's University, Sarisha, South 24 Parganas, West Bengal, India \\ Email: yasminkhatun2093@gmail.com \\ ${ }^{2}$ Associate Professor, Department of Geography, \\ Diamond Harbour Women's University, Sarisha, South 24 Parganas, West Bengal, India \\ Email: ghoshshovan80@rediffmail.com
}

\begin{abstract}
Access to health in low and middle income countries shows a lack of proper evidence on ways to reduce limiting barriers, especially those on the demand and related to the lack of education and information, the cost of access and cultural issues. These problems can be attributed directly to women's lower average incomes to their greater need for, and use of, health care services. The present paper seeks to explore the barriers of financial access to utilisation of health care services to women in rural areas of west Bengal, India. Outline the issues pertaining to distance, time and out-of-pocket expenditure for outdoor patient and indoor patient department treatment of women. The analysis of economic class using wealth index of women was the domain of analysis. Face to face interview of 200 women were conducted with a structured questionnaire. Average distance to sub divisional and rural hospital was far and wide, and also travel time was higher to go health service centre. Heavy reliance was there on rural medical practitioners and local sub centre for all health services need of the women. Financial burden of out of pocket expenditure of women was significantly associated with level of poverty.
\end{abstract}

Key words: Financial Barriers, Health Care Services, Distance, Rural Area Women

\section{Introduction}

The socio-economic development of a country, among other things, largely depends on the quality of human resources. The quality of human resources can not only be visualized in terms of educational, and technological skills that it possesses, but also by the status of its health (Rajaswari and Sinha, 1993). Poverty and health care is a common subject of research and policy, often using different definitions of poverty and health care access (Peter's et.al 2008). Welfare has focussed its attention on improving the primary health services by channelizing adequate financial and manpower resources for making the health services more accessible and affordable to the poor people. (De. 2014). The term affordability, as used in ordinary life, implies that the primary reason someone chooses not to purchase a good or service is that the person does not have the ability to pay for it (Glied, 2009). Factors that prevent women in developing countries from getting the health care include; unavailability and/or inaccessibility of health services, un-affordability of the services because they are too expensive or reaching them is too costly (direct fees as well as the cost of transportation, drugs, and supplies), multiple demands on the time that will be spent on health care seeking, low status of women (Akalu et.al 2016). The scarcity of vehicles, especially in remote areas, and poor road conditions can make it extremely difficult for women to reach even relatively nearby facilities. Walking is the primary mode of 
transportation, even for women in labour (Olayinka et.al 2013). Most of the patients cannot pay for basic care they received at government facilities but may not be willing to pay for treatment they see as effective convenient or accessible than that obtainable from traditional healers (Muelaet. et.al 2000). A review on access to health in low and middle income countries shows a lack of proper evidence on ways to reduces limiting barriers, especially those on the demand and related to the lack of education and information, the cost of access and cultural issues (Cormick.et.al 2012). Against these backdrops, the present paper concentrates on the problem of affordability to health care services of women in a rural set up of India. The paper has been bifurcated into three sections to unfold the dynamicity of financial access. Section-I depicts the socio demographic characteristics of women. Section-II outlines the issues pertaining to distance, time and out-of-pocket expenditure for outdoor patient and indoor patient department treatment of women. The analysis of economic class using wealth index of women is the domain of analysis in section-III. All these financial barriers were tried to be intricately woven out in the research work.

\section{Study Area}

The District of South 24 Parganas (Figure 1) came into existence on March 1, 1986. The southern part of the district covers dense mangrove forests and the entire district is characterized by heterogeneity in terms of physical, socio-economic and cultural profiles combined with unique geographical location. South 24 Parganas District possesses 5 Subdivisions, 7 municipalities, 29 Blocks, and 312 gram panchayats. Canning I Block (22ำ12' $\mathrm{N}$ to $22^{\circ} 24^{\prime}$ and $88^{\circ} 30^{\prime} \mathrm{E}$ to $88^{\circ} 42^{\prime} \mathrm{E}$ ), called the gateway of Sundarban, is the headquarters of the Canning sub-division of South 24 Parganas District. As per 2011 Census of India, Canning-I CD block (Figure 1) had a total population of 304,724, of which 181,508 were rural and 123,216 were urban. There were $51 \%$ males and $49 \%$ females. The total literacy in Canning-I CD block was $71 \%$, with female literacy rate $44 \%$ and male literacy rate $56 \%$. The block possesses 1 rural hospital and 56 Sub centres, spread over various pockets of the block.

Figure 01: Location Map of the Study Area

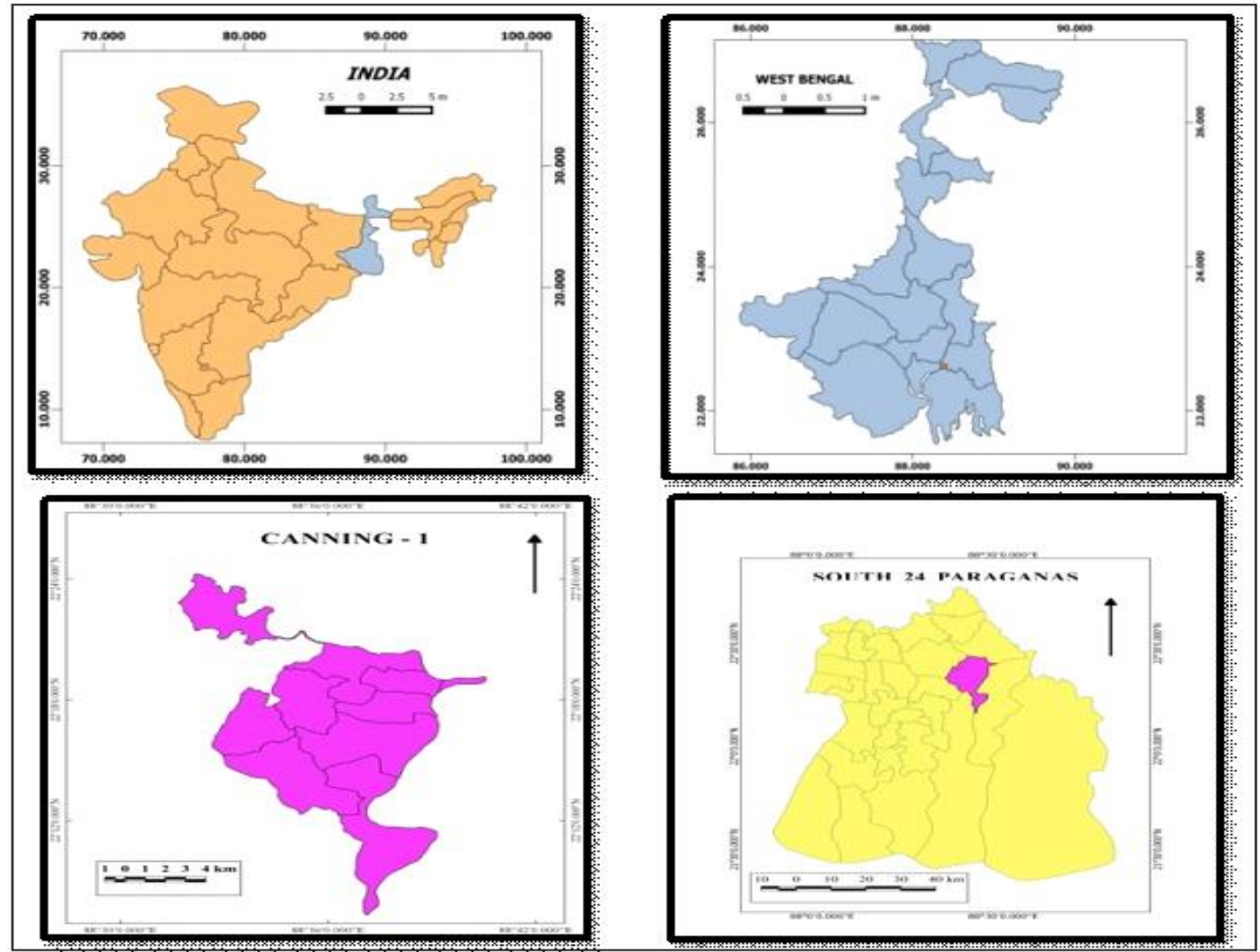




\section{Methodology}

A cross sectional field study was carried out in eleven purposively selected villages of Canning-I rural Community Development Block. A stratified sampling approach was adopted to study a total of 200 women for our study. Women were selected from 3 age groups pertaining to less than $20,20-40$, and $40-60$ age groups. The weightage to selection among age groups were given more on the age groups between 20-60 years, for this group mainly correspond to the reproductive age of women. Face to face interview with all participants were conducted with a structured questionnaire, that considered three major parts namely:

1. Women's socio-demographic characteristics included age, education, family structure, and family income.

2. Distance time and out of -pocket - expenditure for outdoor patient department and indoor patient department.

3. Socio- economic class of women with the NFHS wealth index is based on the following 33 assets and housing characteristics.

\section{RESULTS AND DISCUSSIONS \\ Section-I Socio-Demographic Characteristics of Women}

The mean age of women was 32.54 and \pm 11.70 SD years (Table 1). Most of the women were married and belonged to Hindus and Category of SC (Scheduled Caste) community. Women's education registered mostly up to primary level. Average number of family member was found to the tune of 4 . Families were mainly engaged in daily labour activities. The average monthly income was found to be five thousand. The families stayed at their own house at least for more than 20 years. Most of the area was covered by unmetalled road. The average distance of railway station was close to $7 \mathrm{~km}$, and the time spent of travelling to hospital averaged more than 1 hour. Sometime transport facilities after sunset cease to exist. The average distances sub divisional hospital was close to $5 \mathrm{~km}$. Women have problems related to distance and access to health care services, for metalled roads was insufficient. Hospital was far and wide, heavy reliance was there on rural medical practitioners and local sub centre for all health services need of the women.

Table 01: Socio-Demographic Characteristics of Women

\begin{tabular}{|l|c|c|}
\hline Name of Variables & Mean & Standard Deviation \\
\hline Age & 32.54 & 11.70 \\
\hline Marital status & 2.18 & .783 \\
\hline Religion & 1.38 & .486 \\
\hline Caste & 1.600 & .951 \\
\hline Education qualification & 1.68 & .526 \\
\hline No of family members & 4.27 & 1.45 \\
\hline Occupation & 2.71 & 1.70 \\
\hline Monthly income & 1.42 & 2782 \\
\hline Duration of stay & 2.07 & 0.79 \\
\hline Prefer mode of transport & 5.08 & 3.01 \\
\hline Types of road & 1.84 & 0.36 \\
\hline Distance to railway station & 6.905 & .773 \\
\hline Time spent travelling to health centre & 1.35 & .641 \\
\hline Transport facility after sunset & 2.48 & .701 \\
\hline Distance to SD Hospital & 4.94 & .432 \\
\hline
\end{tabular}

Source: Computation by Author, 2020

\section{Section-II Distance, Time and Out-of-Pocket Expenditure for Outdoor Patient and Indoor Patient Department Treatment of Women}

Affordability of women's health care service will be analysed in terms of distances, time and out of -pocket expenditure for different health service providers. For outpatient treatment, (Table 2) the mean distance to health care providers was lowest both for RMPs and sub 
centres. Average distance to a sub divisional hospital and rural hospital was close to 20 $\mathrm{km}$. Mean time required to travel was also least for the sub centre, the average time to go both rural and sub divisional hospital was more than one hour. The mean transport expenditure was also least for visiting sub centre than any other providers. Out of pocket expenditure (Table 3) for seeking care of sub divisional hospital was double than seeking care for RMPs. It was also noted that more than 70 percent of OPD care is provided by the RMPs and only 30 percent by sub divisional hospital.

For hospitalisation episodes (Table 4) of women's in the last 30 days, the mean distance required to travel for IPD treatment was also least for the RMP than any other providers. The average distance to a sub divisional hospital was almost 1.10 times than that of RMPs. Mean time required to travelling for IPD treatment was also least for the RMPs and time to sub divisional hospital was seven times higher. Average transport expenditure (Table5) was also least for the RMPs and the highest to the sub divisional hospital.

Table 02: Distances and Time for Outdoor Patient Department Treatment of Women's in Last $\mathbf{3 0}$ days

\begin{tabular}{|l|c|c|c|}
\hline Mean Distances (KM) & \multicolumn{2}{c|}{ Mean Time (Min.) } \\
\hline Provider & Total & Provider & Total \\
\hline RMP & 2 & RMP & 20 \\
\hline SD Hospital & 19 & SD Hospital & 111 \\
\hline Rural Hospital & 20 & Rural Hospital & 117 \\
\hline Sub centre & 1 & Sub centre & 16 \\
\hline
\end{tabular}

Source: Computed by Authors, 2020

Table 03: Transport and Total Out of Pocket Expenditure for OPD Treatment of Women's in Last 30 days

\begin{tabular}{|l|c|c|c|}
\hline \multicolumn{2}{|l|}{ Mean Transport Expenditure (Rs.) } & \multicolumn{2}{|c|}{ Mean Total Expenditure (Rs.) } \\
\hline Provider & Total & Provider & Total \\
\hline RMP & 25 & RMP & 201 \\
\hline SD Hospital & 104 & SD Hospital & 403 \\
\hline Rural Hospital & 107 & Rural Hospital & 265 \\
\hline Sub centre & 10 & Sub centre & 15 \\
\hline
\end{tabular}

Source: Computed by Authors, 2020

Table 04: Distances and Time for Indoor Patient Department Treatment of Women's in last 30 days

\begin{tabular}{|l|c|c|c|}
\hline \multicolumn{2}{|l|}{ Mean Distances $(\mathbf{k m})}$. & \multicolumn{2}{c|}{ Mean Time (Min.) } \\
\hline Provider & Total & Provider & Total \\
\hline RMP & 2 & RMP & 15 \\
\hline SD Hospital & 21 & SD Hospital & 105 \\
\hline Rural Hospital & 23 & Rural Hospital & 110 \\
\hline Sub centre & 0 & Sub centre & 0 \\
\hline
\end{tabular}

Source: Computed by Authors, 2020

Table 05: Transport and Total out of Expenditure for IPD Treatment of Women's in

\begin{tabular}{|l|c|c|c|}
\multicolumn{5}{c|}{ Last $\mathbf{3 0}$ Days } \\
\hline Mean Transport Expenditure (Rs.) & \multicolumn{2}{c|}{ Mean Total Expenditure (Rs.) } \\
\hline Provider & Total & Provider & Total \\
\hline RMP & 50 & RMP & 310 \\
\hline SD Hospital & 170 & SD Hospital & 512 \\
\hline Rural Hospital & 190 & Rural Hospital & 565 \\
\hline Sub centre & 0 & Sub centre & 0 \\
\hline
\end{tabular}

Source: Computed by Authors, 2020 
The study discussed on affordability of health care services to women for outpatient care in last 30 days. Average distance to sub divisional and rural hospital was far and wide, and also travel time was higher to go health service centre. For inpatient care in last 30 days, women's had problem related to distance and travel time to access health service centre. Average expenditure was found to be higher for both rural and sub divisional hospital.

\section{Section-III Socio-Economic Class using Wealth Index}

From the quintile index (Table 6) the household can be divided into three zones, i.e. Poorest Quintile, Poor quintile and middle quintile. Accordingly, fewer no of the households falls in the poorest quintiles, and large majority are found in the Poor Quintiles. Only $20 \%$ of the households are found to be at middle quintiles. The study included 200 households from Canning rural Community Development Blocks of South 24 Parganas District. From these households 200 women fulfilling the inclusion criteria were interviewed. Sixty women (80\%) were married. The mean age was respondent mothers was 32 years, about $164(82 \%)$ of the women was illiterate, only $36(18 \%)$ of women have formal education. Most of the women were housewives. Daily labourer was the major economic activity of the households.

Table 06: Socio-Economic Class using Wealth Index

\begin{tabular}{|l|c|c|}
\hline Wealth Index & No. of House hold & Percentage of House hold \\
\hline Quintile 1 Poorest & 28 & 14 \\
\hline Quintile 2 Poor & 132 & 66 \\
\hline Quintile 3 Middle & 40 & 20 \\
\hline Total & 200 & 100 \\
\hline
\end{tabular}

Source: Computed by Authors, 2020

Among the women included the primary survey (Table 7) regarding affordability issues, there was large variation in monthly maternal health expenditures and total household expenditures among those in the lower and upper quintiles. Households of lower wealth quintiles were found to be paying relatively significant than those found in the higher quintiles. The median monthly household proportion of expenditures for the first quintile 2650 rupees, while households in the third quintile spend two and half times more than those in the first quintile. Similarly, the median maternal out of pocket expenditure across the wealth quintiles had an increasing pattern as the wealth quintiles increased. The absolute expenditure of third quintile the proportion of their monthly income was found to be lower for those in the higher income quintile compared to the percentage of expenditure. The percentage share of maternal health care expenditure decreased as the wealth index increased. Women from the two lower quintiles on average paid $43.25 \%$ of their expenditure for maternal care while those in the third quintile paid $13.5 \%$ of their expenditure respectively. Still maternal expenditures constitute substantial proportion of expenditure and this is due to the fact that households do not solely depend on their regular monthly income to pay unexpected health care costs. To finance the cost, they usually borrowed from relatives, neighbours or from local money lenders. In case, the expenditure was so large that they could not finance by these means they resort to sell their assets.

Table 07: Average Monthly Total and Maternal Health Expenditures across Wealth Quintiles at Different Health Public and Private Health Facilities of Women

\begin{tabular}{|l|c|c|c|c|}
\hline Wealth Quintile & $\begin{array}{c}\text { Total } \\
\text { Expenditure }\end{array}$ & $\begin{array}{c}\text { Monthly Health } \\
\text { Expenditure }\end{array}$ & $\begin{array}{c}\text { Maternal health } \\
\text { Expenditure }\end{array}$ & $\begin{array}{c}\text { Percentage of } \\
\text { Maternal Health } \\
\text { Expenditure }\end{array}$ \\
\cline { 2 - 4 } & Median & Median & Median & 17.5 \\
\hline Quintile 1 Poorest & 2650 & 200 & 60 & 69 \\
\hline Quintile 2 Poor & 4000 & 450 & 300 & 13.5 \\
\hline Quintile 3 Middle & 6000 & 1000 & 600 & \\
\hline
\end{tabular}

Source: Computed by Authors, 2020 
The main source of finance to the health service of women in the first and second quintile proportion borrowing from relatives, while for the third quintile proportion selling household items and animals. Borrowing from money lenders was found to be the last resort since the households had no capacity to pay the high interest rate. Rather than borrowing from the money lenders they preferred to sell articles. They did not solely depend on one source of finance rather they were found to use multiple sources.

Table 08: Main Source of Finance for Health Care Services of Women

\begin{tabular}{|l|c|c|c|c|}
\hline \multirow{2}{*}{ Source of Finance } & \multicolumn{4}{|c|}{ Number of Women in each Wealth Quintile } \\
\cline { 2 - 5 } & $\begin{array}{c}\text { Quintile1 } \\
\text { (Poorest) } \\
\mathrm{N}(28)\end{array}$ & $\begin{array}{c}\text { Quintile 2 } \\
\text { (Poor) } \\
\mathrm{N}(132)\end{array}$ & $\begin{array}{c}\text { Quintile 3 } \\
\text { (Middle) } \\
\mathrm{N}(40)\end{array}$ & Total \\
\hline Own savings & 2 & 7 & 7 & 16 \\
\hline Out of regular income & 2 & 19 & 8 & 29 \\
\hline Borrowing from relatives & 9 & 53 & 8 & 70 \\
\hline Borrowing from money lenders & 6 & 15 & 6 & 27 \\
\hline Selling household items and animals & 4 & 27 & 9 & 40 \\
\hline Selling land of family & 5 & 11 & 2 & 18 \\
\hline
\end{tabular}

Source: Computed by Author, 2020

Utilization of health and family planning service was found to be low among the respondent households. In addition, there are indirect cost of seeking health even if out of pocket expenditure at point of service was assumed to be negligible such as travel, distance and time etc. The opportunity cost of care seeking to the patient or the attendant will be significant since the economic activity was mainly labour. Thus these costs are among the factors that are found to discourage utilization. Out - of pocket payments were the common way of paying for health in developing countries (Akalu. et.al. 2012). These payments have differential impact with respect to health outcomes, usually out-of- expenditures results in financial difficulty by households and these health expenditures poses a major setback to the proper utilization of health care services for a backward rural area where bulk of the households are in the poorest quintile.

\section{Findings and Conclusion}

The study provides an analytical discussion on the financial barriers to access to health care services of women with regard to a Canning-I rural community development blocks in West Bengal state of India. The distribution of out -of -pocket expenditure across the wealth quintiles shows that households having poor socio-economic pay more than their counter-parts in absolute terms. Maternal expenditures constitute substantial proportion of expenditure and this is due to the fact that households do not solely depend on their regular monthly income to pay unexpected health care costs. The health care cost depends on the socio-economic status of the population. However, the proportion of out of pocket expenditure from their total consumption expenditure is higher for the worse-off implying out-of-pocket expenditure regressive. Thus the poor are the most vulnerable as they are less able to recover from financial consequences of out-of-expenditure. The financing system of health care should be based on the principle of cost sharing so that there will be resource pooling among poor and the rich. The government should work the private sector to increase the availability of health services and health care resources including the human resources through private wing and out-sourcing.

\section{References}

1. Akalu, F. Guda, A. Tamiru, M. Mariam, D. H. (2012). Out of pocket payments for Maternal Health in rural Ethiopia: Paradox of free health care un- affordability. School of public health Addid Abba University. 26(1), pp- 252-256.

2. Cormick, G. Kim, N, A. Rodgers, A. Gibbons, L. Buekens, P. Belzin, J. (2012). Interest of Pregnant Women in the USA of SMS text messages for the improvement of prenatal 
and post-natal Care. Journal of Reproductive health: Open Access http://www.reproductive health journal.com 1 content 9/1/9

3. De, D. (2014). Spatial Inequality in health care Infrastructure in Sundarbans, West Bengal. India. Publishing International research journal of social sciences. 3(12), (PP 15-22), 2319-3565

4. District Human Development Report of Retrieved, August 5, from http:// www. isca.in/IJSS/S South 24 Parganas, Retrieved July 30, 2014, From http:// www.wb plan. Gov .in/Human Dev/DHDR/24\% 20pgs South/Chapter\% 2001\% $20 \mathrm{FI}$.

5. District Statistical Handbook Bureau of Applied Economic and Statistics Government of West Bengal, for the year 2011

6. Glied, S. (2009). Mandates and the Affordability of health care. Excellus health plan INC, 46(1), pp- 203-214.

7. Muela, S.H. Mushi, A.K. Ribera, J.M. (2000). The paradox of the cost and affordability of traditional and government health services in Tanzania. Journal of health policy and planning. 15(3), 296-302.

8. Olayinka, A.O, Osaji, T.A, Amos, A.O. Chiedu, E. M. (2014). Awareness and Barriers to Utilization of Maternal health care services among reproductive women in Amassoma Community, Bayelsa State. International journal of Nursing and Midwifery, 6(1), pp 10-15.

9. Peters, D.H, Garg, A, Bloom, G. Walker, D.G, Brieger, W, R Rahaman, M.H. (2008). Poverty and Access to Health Care in Developing Countries http://www.researchgate. net/publication/229569366.

10. Primary census abstract 'Census of India' (2011), House listing and housing Census Schedule. Government of India: Retrieved 22 January 2011.www.censusindia.gov.in

11. Rajeshwari and Sinha, S. (1993). Spatial inequalities in the development of Public Health Care Facilities in Rural Haryana, India: Health care patterns and Planning Edited by Akhtar r. A P H Publishing Corporation, New Delhi. 